\title{
The Application Study of Park Enterprises Credit Risk Evaluation Based on Euclid Approach Degree of Fuzzy Matter-element Model
}

\author{
Li Zhou*, Bisong Liu, Yan Zhao and Xianghua Li \\ China national institute of standardization, Beijing, China \\ ${ }^{*}$ Corresponding author
}

\begin{abstract}
Based on the thorough analysis of the internal and external factors which affects the enterprise credit level, the scientific and systematic evaluation index system was established. By adopting the fuzzy matter-element analytical method which especially suits the multi-index and incompatibility issue, the evaluation model was built. The comprehensive integrated weighting method was applied for the determination of the index weight. Meanwhile, the subjective and objective information were considered comprehensively to elaborate the inherent law of the park enterprise credit risk evaluation, which provide practical approach for the park enterprise credit level rating research.
\end{abstract}

Keywords-credit risk evaluation; fuzzy matter-element model; index weight

\section{INTRODUCTION}

The essence of market economy is credit economy, and market economy development process is the process of the credit formation and deepening. From the perspective of modern economics, as one type of contractual relationship, the major characteristic of the credit relation is that the credit provider transfers its property right to the trustee. At the same time, the trustee is committed to giving the credit provider the relevant compensation within the dated stipulated date according to the stipulation of the contract. To some extent, the essence of the credit is the promise during the process of the property intertemporal trade and the trading of the "current actual property "of the credit provider and the "future property" of trustee to achieve the reasonable allocation of property between "current" and "future"[1].

During China market economy development process, credit loss will cause serious consequences and eventually impede the healthy and sustainable development of the economy. The serious credit loss not only results in the deterioration of social conscience and serious lack of customers' confidence, which will increase the trading cost in the market trade. The raising of the trading cost will drive more people to make up their loss by dishonest behavior, which will form a vicious cycle and cause great financial losses of our country [2]. As the development body of the current local park economy, the park enterprise credit level will directly influence the park overall economy development level. Due to some degree of aggregation of the park enterprise, the park enterprise credit level is influenced by both internal and external factors. Therefore, objective and reasonable analysis and evaluation of park enterprise credit level is significant for determining the park economy development level correctly and then make the park enterprise credit development plan accordingly, issuing relevant park industry development policy and measures, rationally allocating the park enterprise credit resource, promoting competitiveness of regional enterprise and driving the regional economy development.

\section{PARK ENTERPRISE CREDIT EVALUATION INDEX}

The definition of "credit "in national standard CreditGeneral Vocabulary GB/T 22117-2008 is: The ability of getting capital, materials, or service without immediate payment or guarantee based on trust. This ability is on condition that the trustee's promise to repay within the agreed period. Note: On broad sense, credit means principle of good faith is widely used in society. On narrow sense, credit belongs to economy scope. It reflects a kind of ability, which is founded on the trade. The broad sense credit indicates the widely use of the principle of good faith, which includes integrity scope. For the scientific evaluation of enterprise quality rating, we need to establish scientific, rational and feasible credit risk evaluation model, which means we need to find out the key factors forming the enterprise credit.

An enterprise, regardless its large or small scale, long or short history, it shall reflect its credit characteristic in some aspects, and this characteristic will determine its credit form. According to the common enterprise credit "3C" (Character, Capacity and Capital of enterprise) evaluation model, combing the definition of credit, it is not to see that the factors influencing the enterprise credit level include enterprise faithkeeping will, contractual capacity, and faith-keeping performance [3]. We initially establish park enterprise credit risk evaluation basic model based on these three aspects. Among the three factors, enterprise faith-keeping will is the fundamental influence factor, which determines the enterprise faith-keeping performance and result; the enterprise contractual capacity is the basic influence factor, which determines whether the enterprise can live up to the promise or not; the enterprise faith-keeping performance is the final influence factor, which is the behavioral expression of faith keeping and the determination standard for the faith keeping.

In this evaluation model, the evaluation object is the enterprise credit status. Therefore, the primary credit factor is 
the enterprise faith-keeping will status, which includes the qualification enterprise must possess, administrative licensing requirement the enterprise or its products shall comply with, laws and regulations requirements, enforce management requirement etc. Whether these requirements can be met or not is the most basic requirements for enterprise faith-keeping, and this equals to the enterprise character in "3C" evaluation model. In addition, the enterprise shall posses corresponding contractual capacity such as soundness of enterprise quality management system, scientific and technological level, financial management, safety management, and this factor determines whether the enterprise has the ability to produce the products meeting the customers' requirements, which is equivalent of capability factor of " $3 \mathrm{C}$ model". At last, the enterprise actual faith-keeping performance such as honor receiving status, social responsibility taking status, administrative penalty, which directly reflect enterprise credit status. This status can be obtained and gathered via various channels as follows: law enforcement supervision, supervision and random checking, credit file.

To make sure that the evaluation index system truly reveal the park enterprise credit level connotation and correctly reflect park enterprise credit level essence and operation law, the built index system shall include the above elements influencing the enterprise credit level and their interrelation and hierarchical structure shall be distinguished well. Therefore, we build the park enterprise credit index system around three key factors (park enterprise faith-keeping will, contractual capacity and faith-keeping performance) which influence park enterprise credit level. What's more, we divide them into three types, and further select typical indexes reflecting these three factors and form a scientific, systematic, and common-used park enterprise credit level evaluation index system including three levels of objective level, factors level, index level, three main category, 6 small category according to the principles such as finality, scientificity, systematicness, maneuverability and comparability. For detail, please refer to Table 1.
TABLE I. PARK ENTERPRISE CREDIT RISK EVALUATION INDEX SYSTEM

\begin{tabular}{|c|c|c|}
\hline $\begin{array}{c}\text { Objective } \\
\text { level }\end{array}$ & Factors level & Index level \\
\hline \multirow{3}{*}{$\begin{array}{l}\text { Park } \\
\text { enterprise } \\
\text { credit level }\end{array}$} & $\begin{array}{l}\text { Enterprise faith- } \\
\text { keeping will }\end{array}$ & $\begin{array}{l}\text { Enterprise basic information } C_{1}, \\
\text { qualification license information } \\
c_{2} \text { (Including industry license, } \\
\text { qualification information, enforce } \\
\text { management requirement etc.) }\end{array}$ \\
\hline & $\begin{array}{l}\text { Enterprise } \\
\text { contractual } \\
\text { capacity }\end{array}$ & 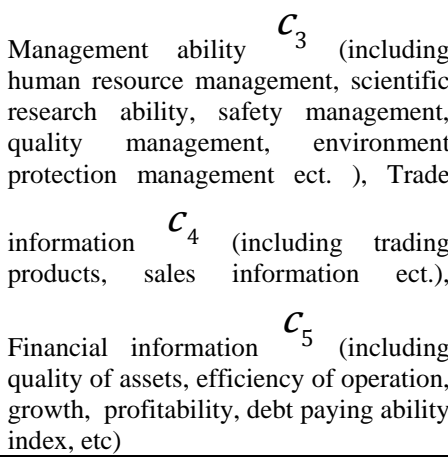 \\
\hline & $\begin{array}{l}\text { Enterprise faith- } \\
\text { keeping } \\
\text { performance }\end{array}$ & $\begin{array}{lcc} & C_{6} \\
\text { Credit record } & \\
\text { information, social responsibility } \\
\text { information, judiciary record, } \\
\text { administrative penalty information etc. ) }\end{array}$ \\
\hline
\end{tabular}

The park enterprise credit level itself is a vague concept. There are many influence factors. Its evaluation index is a complex multi-component system, which includes quantitative index and qualitative index of different change rules, among which qualitative index has vagueness it cannot be expressed in an accurate value and this results in some uncertainty and vagueness for the evaluation result. Therefore, we shall start the evaluation of the park enterprise credit level from its vagueness and incompatibility of evaluation result. Matter-element analysis theory studies the matter-element and its change rule, which is effective method for the incompatible issues in reality, and it suits well the issues with combination of quantitative index and qualitative index and other index [4].

\section{EUROPEAN Close Degree FuZZY-ELEMENT MODEL BUILDING}

A. Build Composite Fuzzy-element Matrix $R_{n m}$

The elements are triple array $R=(M, C, x)$ consisting of given plan or matter $M$, optimized index $C$ (eigenvector) and index value $x$ (eigenvector). If the index characteristic value $x$ has some uncertainty and vagueness, $\mathrm{R}$ will be fuzzy-element [5]. Assembly of $\mathrm{m}$ plans or matters corresponding $\mathrm{n}$ index values will form a composite fuzzy-element matrix, and it is as follows: 


$$
R_{n m}=\left[\begin{array}{ccccc} 
& M_{1} & M_{2} & \cdots & M_{m} \\
c_{1} & X_{11} & X_{12} & \cdots & X_{1 m} \\
c_{2} & X_{21} & X_{22} & \cdots & X_{2 m} \\
\vdots & \vdots & \vdots & & \vdots \\
c_{n} & X_{n 1} & X_{n 2} & \cdots & X_{n m}
\end{array}\right]
$$

\section{B. Preferred Degree of Membership Fuzzy-element Matrix $R_{\text {nm }}^{\prime}$ Confirmation.}

Conduct the calculation of preferred degree of membership on evaluation index $X_{i j}$ in each plan or matter and the matrix consisted $s$ of preferred degree of membership is called preferred degree of membership fuzzy-element matrix [6] and it is as follows:

$$
R_{n m}^{\prime}=\left[\begin{array}{ccccc} 
& M_{1} & M_{2} & \cdots & M_{m} \\
c_{1} & \mu_{11} & \mu_{12} & \cdots & \mu_{1 m} \\
c_{2} & \mu_{21} & \mu_{22} & \cdots & \mu_{2 m} \\
\vdots & \vdots & \vdots & & \vdots \\
c_{n} & \mu_{n 1} & \mu_{n 2} & \cdots & \mu_{n m}
\end{array}\right]
$$

In the calculation of preferred degree of $\mu_{i j}=\frac{x_{i j}}{\max x_{i j}}$ is profit index; $\mu_{i j}=\frac{\min x_{i j}}{x_{i j}}$ is cost index.

\section{Difference of Two Squares Fuzzy-element Matrix Formation}

Under ideal condition, the index $\mu_{i j}=1, S_{i j}=\left(\mu_{i j}-1\right)^{2}$ forms difference of two squares fuzzy-element, and it is as follows:

$$
R_{s_{n m}}=\left[\begin{array}{ccccc} 
& M_{1} & M_{2} & \cdots & M_{m} \\
c_{1} & S_{11} & S_{12} & \cdots & S_{1 m} \\
c_{2} & S_{21} & S_{22} & \cdots & S_{2 m} \\
\vdots & \vdots & \vdots & & \vdots \\
c_{n} & S_{n 1} & S_{n 2} & \cdots & S_{n m}
\end{array}\right]
$$

\section{Index Weight Calculation}

1) Specialist investigation method calculates the qualitative weight coefficient

The specialist investigation method is simple, intuitive and feasible. The detailed steps are:

a) Employ the specialist to fill in the investigation form: During the investigation, investigation on each specialist shall be don separately to avoid the discussion and points changing between specialists [7]. The $a_{i j}$ meets requirement of $\sum_{i=1}^{n} a_{i}=1, a_{i j}$ means the degree of importance score give by specialist $\mathrm{j}$ on the index I of the evaluation object.

b) Summarize the questionnaire on specialists: Summarize the evaluation index $a_{i j}$ degree of importance on all the investigated specialists.

c) Calculate the degree of importance coefficient of index $\alpha_{i}$

$$
\alpha_{i}=\sum_{i=1}^{n} a_{i j} / \sum_{i=1}^{n}\left(\sum_{j=1}^{m} a_{i j}\right), i=1,2, \cdots, n
$$

2) Calculate the quantitative weight coefficient by entropy weight method

The entropy weight method belongs to objective weighting method, and its calculation is based on objective information and it is not influenced by the subjective preference of the specialist or the evaluator [8]. Its steps are as follows:

a) Build matter element matrix $R_{n m}$.

b) Normalize the matter element matrix

$$
b_{i j}=\frac{X_{i j}-X_{\min }}{X_{\max }-X_{\min }}
$$

In the formula: $X_{\max } 、 X_{\max }$ respectively are the best or the worst under different evaluation object of the same index.

c) Confirm the entropy of the evaluation index.

$$
\begin{gathered}
H_{i}=-\frac{1}{\ln m}\left(\sum_{j=1}^{m} f_{i j} \ln f_{i j}\right), i=1,2, \cdots, n, \\
j=1,2, \cdots, m
\end{gathered}
$$

In the calculation: $f_{i j}=b_{i j} / \sum_{i=1}^{n} b_{i j}$ 
d) Calculate the entropy weight of evaluation index

$$
\beta_{i}=\frac{1-H_{i}}{n-\sum_{i=1}^{n} H_{i}, \text { and }} \sum_{i=1}^{n} \beta_{i}=1
$$

\section{E. Composite Weight Coefficient Blending Method}

To make the composite weight reflect both the objective and subjective weight based on minimum authentication information [9], composite weight calculation formula is:

$$
\omega_{i}=\sqrt{\alpha_{i} \beta_{i}} / \sum_{i=1}^{n} \sqrt{\alpha_{i} \beta_{i}}, i=1,2, \cdots, n
$$

\section{F. The Comprehensive Evaluation Based on European Close Degree}

The close degree is the degree of closeness between the evaluated object and the standard object. The bigger the close degree, the smaller of it difference; otherwise, the bigger of its difference [10]. The index $\mu_{i j}=1$ under ideal condition, the standard object close degree is 1 . When the degree of closeness of park enterprise credit is near 1 , it means that the high credit level of the park enterprise. The close degree can be calculated according to square difference fuzzy-element and the entropy weight of each evaluation index.

$$
\begin{gathered}
R_{D}=\left[\begin{array}{ccccc} 
& M_{1} & M_{2} & \cdots & M_{m} \\
D_{j} & D_{1} & D_{2} & \cdots & D_{m} \\
& & & &
\end{array}\right] \\
D_{j}=1-\sqrt{\sum_{i=1}^{n} \omega_{i} S_{i j}}, j=1,2, \cdots, m
\end{gathered}
$$

\section{APPLICATIONS}

Whether the selection of the evaluation index is scientific, comprehensive and rational will directly affects the comprehensive evaluation result: Too many indexes will cause the repeatability index, enlarge the relevant index weight, and increase the complexity and error of the data collection of the comprehensive evaluation. Too few indexes will make the index lack of representativeness and cause one-sidedness [11]. The index selection shall be based on the motivated, comprehensive and feasible principle.

6 enterprises of some park credit risk evaluation index value after non dimensionalization is as follows.
TABLE II. PARK ENTERPRISE CREDIT RISK EVALUATION INDEX VALUE

\begin{tabular}{|l|l|l|l|l|l|l|}
\hline Index & $\begin{array}{c}\text { Enterpr } \\
\text { ise 1 }\end{array}$ & $\begin{array}{c}\text { Enterp } \\
\text { rise 2 }\end{array}$ & $\begin{array}{c}\text { Enterp } \\
\text { rise 3 }\end{array}$ & $\begin{array}{c}\text { Enterp } \\
\text { rise 4 }\end{array}$ & $\begin{array}{c}\text { Enterp } \\
\text { rise 5 }\end{array}$ & $\begin{array}{c}\text { Enterp } \\
\text { rise 6 }\end{array}$ \\
\hline$C_{1}$ & 0.17 & 0.15 & 0.18 & 0.16 & 0.16 & 0.17 \\
\hline$C_{2}$ & 0.23 & 0.12 & 0.18 & 0.16 & 0.13 & 0.18 \\
\hline$C_{3}$ & 0.04 & 0.41 & 0.04 & 0.04 & 0.23 & 0.24 \\
\hline$C_{4}$ & 0.26 & 0.06 & 0.16 & 0.24 & 0.04 & 0.23 \\
\hline$C_{5}$ & 0.18 & 0.11 & 0.15 & 0.20 & 0.14 & 0.22 \\
\hline$C_{6}$ & 0.15 & 0.12 & 0.18 & 0.21 & 0.12 & 0.24 \\
\hline
\end{tabular}

During the subjective weight calculation, we employed 6 specialists to score for the park enterprises credit index weight and the summary sheet table 3 is follows:

TABLE III. SPECIALIST'S INVESTIGATION SUMMARY SHEET

\begin{tabular}{|l|c|c|c|c|c|c|}
\hline Specialists & $\boldsymbol{c}_{1}$ & $\boldsymbol{c}_{2}$ & $\boldsymbol{C}_{3}$ & $\boldsymbol{c}_{4}$ & $\boldsymbol{c}_{5}$ & $\boldsymbol{C}_{6}$ \\
\hline 1 & 0.40 & 0.15 & 0.05 & 0.15 & 0.20 & 0.05 \\
\hline 2 & 0.30 & 0.05 & 0.10 & 0.20 & 0.15 & 0.20 \\
\hline 3 & 0.35 & 0.15 & 0.05 & 0.10 & 0.25 & 0.10 \\
\hline 4 & 0.30 & 0.15 & 0.10 & 0.15 & 0.15 & 0.15 \\
\hline 5 & 0.40 & 0.20 & 0.05 & 0.10 & 0.15 & 0.10 \\
\hline 6 & 0.35 & 0.10 & 0.05 & 0.15 & 0.25 & 0.10 \\
\hline
\end{tabular}

According to evaluation process steps we calculate the subjective and objective weight and blend the composite weight via formula (8), and the blending weight refers to table 4. From table 4 we find: In the entropy weight method, the bigger the index $c_{1}$ weight, the smaller the index weight $c_{1}$. Meanwhile, in the specialist investigation method, the bigger the index $c_{1}$ weight, the smaller the index $c_{3}$ weight. From the analysis of the data, we find that, in the entropy weight method, the bigger the dispersion degree of evaluation index value, the bigger the calculated weight. By comparing the subjective, objective and composite weight, we can find: The composite weight lies between subjective and objective weight, the sequencer procedure not only respects the will of specialist but also reflects the objective value.

TABLE IV. COMPOSITE WEIGHT BLENDING RESULT

\begin{tabular}{|l|c|c|c|c|c|c|}
\hline \multicolumn{1}{|c|}{ Weight } & $c_{1}$ & $c_{2}$ & $C_{3}$ & $c_{4}$ & $C_{5}$ & $C_{6}$ \\
\hline $\begin{array}{l}\text { Entropy } \\
\text { weight } \\
\text { method }\end{array}$ & 0.1155 & 0.1433 & 0.2438 & 0.1355 & 0.1270 & 0.2348 \\
\hline $\begin{array}{l}\text { Specialist } \\
\text { investigation } \\
\text { method }\end{array}$ & 0.3500 & 0.1333 & 0.0667 & 0.1417 & 0.1917 & 0.1167 \\
\hline $\begin{array}{l}\text { Composite } \\
\text { weight }\end{array}$ & 0.2169 & 0.1491 & 0.1375 & 0.1495 & 0.1683 & 0.1786 \\
\hline
\end{tabular}


We calculate the park enterprise credit level close degree according to formula (9) and rank the park enterprise credit status and it refers to table 5. From table 5 we can find: The credit level close degree of enterprise 5 is 0.6724 , which is closest to the standard object close degree 1 ; so the credit level of enterprise 5 is the highest, and the respectively rank is enterprise2, enterprise3, enterprise4, enterprise 1 and enterprise 6. By comparing table 2 enterprise credit risk evaluation index we can find: Although index $c_{1}$ of enterprise 2 is lowest, but its index $c_{3}$ and index $c_{3}$ is higher compared to enterprise 5.The index $c_{1}, c_{3} c_{5}$ and $c_{6}$ of enterprise 6 is all the highest, so the credit risk of enterprise 6 is the highest and its credit is worst. The rank reflects the actual credit status of the 6 enterprises.

TABLE V. THE CREDIT CLOSE DEGREE OF 6 ENTERPRISES

\begin{tabular}{|l|c|c|c|c|c|c|}
\hline Index & $\begin{array}{c}\text { Enterp } \\
\text { rise 1 }\end{array}$ & $\begin{array}{c}\text { Enterp } \\
\text { rise 2 }\end{array}$ & $\begin{array}{c}\text { Enterp } \\
\text { rise 3 }\end{array}$ & $\begin{array}{c}\text { Enterp } \\
\text { rise 4 }\end{array}$ & $\begin{array}{c}\text { Enterp } \\
\text { rise 5 }\end{array}$ & $\begin{array}{c}\text { Enterp } \\
\text { rise 6 }\end{array}$ \\
\hline $\begin{array}{l}\text { Close } \\
\text { degree } \\
\text { value }\end{array}$ & 0.5751 & 0.6276 & 0.6220 & 0.5770 & 0.6724 & 0.4451 \\
\hline
\end{tabular}

\section{CONCLUSION}

We adopt the European close degree fuzzy-element model method to evaluate and analyze the park enterprise credit risk level thorough the application research on the park enterprise credit risk, according to the evaluation index vagueness and incompatibility of different indexes. For the determination of the index weight, we adopt the composite weighting method by combining the specialist investigation and object entropy weight method, which comprehensively considers the subjective and objective information and reflects the actual credit level of the park enterprise, provide scientific basis and decision support for the government department to promote the regional enterprise credit level and it is feasible and practical.

\section{ACKNOWLEDGMENT}

Li Zhou, Bisong Liu, Yan Zhao and Xianghua Li thank National Key R\&D Program of China.

\section{REFERENCES}

[1] Zhou Li, Ye Ruyi, Xian kuitong, Wang Yanfeng. 2010. Theory and Practice of Quality Credit System Construction,1st Edition, China zhijian publishing house.

[2] Zhou Li. 2014. Understanding of 'Implement specifications for enterprise quality trustworthiness management'[J], China quality supervision, 04,pp 18-21.

[3] GB/T 31863-2015, Evaluation index of enterprise quality credit.

[4] Zhou Tai, Yuan Bo. The Evaluation of Regional Logistics Development Based on Euclid Approach Degree of Fuzzy Matter-element [J]. Logistics Sci-Tech, 2016,39(03):13-17.

[5] JIN Ye-quan;HU Man;WU Qian;JI Yong-qiang. Study on Quantitative Risk Assessment Method of Drilling Well Control Based on Euclid Approach Degree. Science Technology and Engineering , 2014,14(22):176-179+188.

[6] Fu Jinxiang;Liu Conghui;Zhang Rongxin;Song Xiuqiang;Xiao Yanan. Selection of intermediate water treatment processes for pulp and paper industry using the fuzzy matter-element analysis based on eucli approaching degree[J]. Chinese Journal of Environmental Engineering. 2014,8(11):4600-4604

[7] LI Lin,FU Qiang,HE Yanguo. Fuzzy Matterelement Model for Evaluating Sustainable Utilization of Agriculture Water Resources in Xinjiang [J]. Research of Soil and Water Conservation. 2006(04):46-48

[8] LIU Xiang, LI Ping, MING Wen-hui. Application of fuzzy matterelement model to appraisal on high-rise building structural project on the basis of Euclid approach degree theory[J]. Journal of Inner Mongolia University of Science and Technology, 2012,31(04):385-387.

[9] LI Bing, WANG Feng-shan, LI Wei. Method of Air-attack Target Threat and Order Based on Fuzzy-matter Elements Analysis[J]. Aeronautical Computing Technique, 2008(01):12-15.

[10] ZHANG Ding-xue, LIU Xin-zhi, XU Yong-gao, LIAO Rui-quan, LI Qing-ying. Application of Analytical Method of Fuzzy in Reservoir Classification[J]. Journal of Oil and Gas Technology, 2005(05):560562+539-540.

[11] Zhou Li. 2013. Technology Research on Quality Credit Evaluation of the Enterprise with Real-name System. Standard science. 05,pp 77-81. 